\title{
PENGARUH PENGGUNAAN MUSIK ROCK TERHADAP PERTUMBUHAN CABAI MERAH KERITING (Capsicum annum L.)
}

\author{
Andi Asri Ainun ${ }^{1}$ \\ Universitas Muslim Maros, asriainun14699@gmail.com \\ Warda Murti ${ }^{2}$, Sri Maya ${ }^{3}$ \\ Universitas Muslim Maros, wardamurti@umma.ac.id, maya@umma.ac.id
}

\begin{abstract}
Abstrak
Penelitian ini merupakan penelitian eksperimen yang bertujuan untuk mengetahui ada tidaknya pengaruh penggunaan musik rock terhdap pertumbuhan cabai merah keriting (Capsicum annum L). Desain penelitian ini adalah Rancangan Acak Lengkap (RAL), terdiri dua perlakuan dan sepuluh ulangan. Sampel yang digunakan cabai merah keriting dengan 10 bibit tanpa perlakuan dan 10 bibit yang diberi suara musik rock. Musik rock yang digunakan yaitu Korn-It's On dengan kebisingan 56,4 dB setara dengan frekuensi $2348 \mathrm{~Hz}$. Data yang diperoleh dari uji ANOVA yakni, tinggi batang, didapatkan bahwa $F_{\text {hitung }}=64.500$, sedangkan $F_{\text {tabel }}=4.41$, maka $F_{\text {hitung }}>F_{\text {tabel }}$, hasil uji ANOVA jumlah daun, didapatkan bahwa $F_{\text {hitung }}=54.844$, sedangkan $F_{\text {tabel }}=4.41$, maka $F_{\text {hitung }}>F_{\text {tabel }}$, hasil uji ANOVA lebar daun, didapatkan bahwa $F_{\text {hitung }}=27.988$, sedangkan $F_{\text {tabel }}=4.41$, maka $F_{\text {hitung }}>F_{\text {tabel}}$, hasil uji ANOVA berat basah, didapatkan bahwa $F_{\text {hitung }}=35.007$, sedangkan $\mathrm{F}_{\text {tabel }}=4.41$, maka $\mathrm{F}_{\text {hitung }}>\mathrm{F}_{\text {tabel }}$ dan hasil uji ANOVA berat kering, didapatkan bahwa $F_{\text {hitung }}=14.878$, sedangkan $F_{\text {tabel }}=4.41$, maka $F_{\text {hitung }}>F_{\text {tabel. }}$. Hasil penelitian ini menunjukkan bahwa, nilai di setiap parameter pertumbuhan cabai merah keriting diperoleh $\mathrm{F}_{\text {hitung }}>\mathrm{F}_{\text {tabel}}$, sehingga dapat dikatakan bahwa, ada pengaruh penggunaan musik rock terhadap pertumbuhan cabai merah keriting (Capsicum annum L.).
\end{abstract}

\section{Abstract}

This research is an experimental study that aims to determine whether there is an effect of using rock music on the growth of curly red chili (Capsicum annum L). The design of this study was a completely randomized design (CRD), consisting of two treatments and ten replications. The sample used curly red chili with 10 seeds without treatment and 10 seeds with rock music sound. The rock music used is Korn-It's On with a noise of 56.4 $\mathrm{dB}$ equivalent to a frequency of $2348 \mathrm{~Hz}$. The data obtained from the ANOVA test, namely, stem height, it was found that $F_{\text {count }}=64,500$, while $F_{\text {table }}=4.41$, then $\mathrm{F}_{\text {count }}>\mathrm{F}_{\text {table, }}$, the results of the ANOVA test on the number of leaves, it was found that $\mathrm{F}_{\text {count }}=54,844$, while $\mathrm{F}_{\text {table }}=4.41$, then $\mathrm{F}_{\text {count }}>\mathrm{F}_{\text {table, }}$, the results leaf width ANOVA test, it was found that $F_{\text {count }}=27.988$, while $F_{\text {table }}=4.41$, then $F_{\text {count }}>F_{\text {table, }}$, the results of the wet weight ANOVA test, it was found that $F_{\text {count }}=35.007$, while $F_{\text {table }}=4.41$, then $F_{\text {count }}>F_{\text {table }}$ and the dry weight ANOVA test results, obtained that $F_{\text {count }}=14,878$, while $F_{\text {table }}=4.41$, then $F_{\text {count }}>F_{\text {table. }}$. The results of this study indicate that the value for each growth parameter of curly red chili is obtained by $F_{\text {count }}>F_{\text {table, }}$, so it can be said that there is an effect of using rock music on the growth of curly red chili (Capsicum annum L.).

Kata Kunci: cabai merah keriting, musik rock, pertumbuhan 


\section{PENDAHULUAN}

Tanaman cabai (Capsicum annum L.) adalah komoditas tanaman hortikultur yang sangat merakyat, selain mempunyai nilai jual tinggi bagi masyarakat Indonesia, cabai apapun jenisnya tidak dapat dipisahkan dari kebutuhan sehari-hari, salah satu diantaranya cabai merah keriting, hampir setiap hari keluarga Indonesia memanfaatkannya sebagai bahan kelengkapan pada setiap jenis olahan masakan dengan memberi rasa pedas (Suparman, 2006: 1-2). Selain itu juga, cabai pun memiliki banyak khasiat bagi kesehatan yakni sebagai vitamin maupun sebagai obat-obatan (Vebriansyah, 2020: 3). Semakin banyaknya usaha-usaha di bidang masakan, baik dalam bentuk restoran, warung makan, perhotelan, maupun industri masakan instan dan industri saus sambal. Usaha-usaha di bidang tersebut membutuhkan cabai dengan jumlah besar (Suyanti, 2020: 58). Kebutuhan produksi cabai yang setiap hari kian meningkat, membuat para petani melakukan berbagai teknik budidaya, seperti penggunaan varietas unggul, pemakaian pupuk organik maupun an-organik yang dipandang mampu meningkatkan produksi cabai.
Pada umumnya, produksi cabai dengan penggunaan pupuk di dunia pertanian tidak dapat dipisahkan, sebab pupuk adalah zat yang dicampurkan ke dalam media tanam agar kebutuhan nutrisi tanaman terpenuhi dalam meningkatkan produksi (Dwicaksono et al., 2013: 8). Akan tetapi ketergantungan dalam penggunaan pupuk an-organik yang digunakan dengan terus menerus dan tak terkendali akan menyebabkan dampak negatif pada tanaman, sebab tanaman tidak mampu menyerap secara optimal pupuk an-organik. Sisa-sisa pupuk an-organik yang tertinggal dalam tanah dapat berdampak pada kualitas fisik dan kimia tanah seperti tanah akan berstektur kering, keras (tidak gembur) serta tanah bersifat masam, sehingga teknik budidaya dengan penggunaan pupuk an-organik yang secara jangka panjang mengakibatkan produksi cabai menurun (Soekamto \& Fahrizal, 2019). Teknik budidaya dalam mengatasi hal tersebut, salah satunya dapat menerapkan perlakuan fisik yakni pemanfaatan teknologi gelombang suara.

Penggunaan teknologi gelombang suara yang dikenal dengan istilah sonic bloom dapat berdampak positif bagi tanaman yakni tokoh yang menemukan 
pertama kali adalah Dan Carlson 1980.

Di mana sonic bloom merupakan teknologi yang mampu meningkatkan pertumbuhan tanaman dengan cara pemanfaatan frekuensi suara. Penggunaan frekuensi suara dianggap lebih baik dalam membantu tanaman bernapas dengan merangsang mulut daun (stomata) agar tetap terbuka, sehingga kebutuhan nutrisi terpenuhi. Pembukaan stomata akan semakin melebar dengan adanya getaran bunyi (Kadarisman et al., 2011: 464) .

Di Indonesia sendiri, sudah ada yang mengarah dalam pemanfaatan teknologi sonic bloom. Seperti penelitian (Utami, 2012: 6) dengan judul "Aplikasi Musik Klasik, Pop dan Hard Rock Terhadap Pertumbuhan Vegetatif Tanaman Cabai Merah Keriting (Capsicum annuum var.longum)" yang diperoleh bahwa perlakuan musik hard rock berpengaruh sangat nyata dalam meningkatkan pertumbuhan tanaman vegetatif cabai merah keriting dibandingkan dengan musik lainnya yakni musik klasik dan pop. Menurut hasil penelitian dari (Rosalina, 2014: 47) dengan judul "Pengaruh Penggunaan Musik Rock Tehadap Pertumbuhan Cabai Rawit dan Cabai Keriting" mengatakan bahwa musik rock dapat berpengaruh terhadap pertumbuhan cabai rawit dan cabai keriting, dengan cabai keriting lebih unggul. Kemudian hasil penelitian (Damayanti, 2016: 41) dengan judul "Pengaruh Pemberian Suara Garengpung (Dundubia manifera) dengan Intensitas Waktu Tertentu Terhadap Pertumbuhan Tanaman Jahe Merah (Zingiber officinale)" mengatakan bahwa suara garengpung dengan frekuensi $1485-4594 \mathrm{~Hz}$ dapat merangsang pembukaan stomata pada daun jahe merah. Dapat diambil kesimpulan bahwa penggunaan musik rock yang memiliki tingkat kebisingan dengan frekuensi suara yang tinggi dapat mempengaruhi pertumbuhan tanaman. Tujuan penelitian ini adalah untuk mengetahui pengaruh penggunaan musik rock terhadap pertumbuhan cabai merah keriting (Capsicum annum L.). Parameter pertumbuhan tanaman yang ingin diketahui tidak hanya tinggi batang, jumlah daun dan biomassa tanaman. Dalam penelitian ini parameter lebar daun tanaman cabai merah keriting juga diukur.

\section{METODE PENELITIAN}

Jenis penelitiannya adalah penelitian eksperimen. Metode penelitian ini di pakai dalam menemukan pengaruh perlakuan tertentu terhadap perlakuan 
lain dalam situasi yang terkendalikan (Sugiono, 2010).

Desain penelitian yang dipakai yakni menggunakan model Rancangan Acak Lengkap (RAL), terdiri atas 2 perlakuan dengan 10 ulangan, yaitu: $\mathrm{P}_{0}=$ Tanpa Perlakuan Suara Musik, dan $\mathrm{P}_{1}=$ Diberikan Suara Musik Rock. Rancangan ini dipakai apabila suatu unit percobaan tersebut relatif homogen serta ulangan dibangun, tidak menampilkan ketidaksamaan sumber dari keragaman (Made, 2015).

Penelitian ini dilakukan pada bulan April-Mei 2021. Penelitian ini dilaksanakan di halaman rumah penulis yang berlokasi di Jln. Karaeng Pattodo, Kel. Balleangin, Kec. Balocci, Kab. Pangkajene dan Kepulauan.

Adapun populasi yang digunakan yakni 10 gram cabai merah keriting (Capsicum annum L) yang telah disemai selama 17 hari dan telah memiliki 4 buah daun. Jumlah sampel cabai merah keriting (Capsicum annum L.) yang digunakan yakni 10 buah bibit tanpa perlakuan (kontrol) dan 10 bibit perlakuan (eksperimen) dengan jumlah total bibit cabai yang digunakan sebanyak 20 buah.

Pembuatan media tanam, media tanam yang digunakan merupakan campuran tanah dan pupuk kandang dengan perbandingan 2:1. Pupuk kandang sebaiknya sudah matang atau kering. Selanjutnya tanah dibiarkan terkena sinar matahari secara langsung \pm 1-3 hari.

Persiapan pembenihan, benih cabai yang digunakan diperoleh dari toko pertanian. Sebelum biji akan disemai, sebaiknya direndam lebih dahulu dengan air hangat, selama 30-40 menit, kemudian dibungkus dengan kain basah, dan untuk benih yang mengapung saat direndam sebaiknya dibuang. Setelah itu, penyemaian dilakukan di wadah luas yang sudah diberi media tanam. Bibit yang digunakan sudah berumur 17 hari atau sudah memiliki 4 buah daun.

Perlakuan selama satu bulan, sebelum musik dipaparkan, tanaman di masukkan ke dalam kotak yang kedap suara, yang terbuat dari kaca agar cahaya tetap masuk, serta tidak mempengaruhi tanaman kontrol. Musik rock dipaparkan setiap pagi selama 2 jam yakni pada pukul 7.00-9.00 agar penyerapan $\mathrm{CO}_{2}$ lebih efisien dari awal pembukaan stomata. Musik diputar menggunakan bantuan media handphone dan speaker untuk membantu memperjelas suara.

Tanaman kontrol, untuk penanaman tanaman kontrol sama halnya dengan 
tanaman perlakuan, hanya saja tanaman kontrol tidak dipaparkan musik.

Adapun instrumen yang digunakan berupa alat dan bahan sebagai berikut: Alat: 20 buah polybag, 1 buah wadah, 1buah kotak kedap suara/aquarium, alat tulis, penggaris, musik player (musik hard), speaker (pengeras suara), aplikasi audacity, timbangan. Bahan 20 buah biji tanaman cabai, tanah, pupuk kandang, air, kertas milimeter

Teknik pengumpulan data dilakukan dalam waktu satu bulan untuk mengetahui tinggi, jumlah daun, lebar daun serta biomassa tanaman pada saat dipaparkan musik rock dan tanaman kontrol. Pengukuran tinggi tanaman dilakukan selama 3 hari sekali dengan menggunakan alat ukur yakni penggaris, begitu pun untuk jumlah daun maupun lebar daun dihitung setiap 3 hari sekali, khusus untuk perhitungan lebar daun yakni menggunakan metode kertas milimeter, ini dianggap cukup baik pada daun yang memiliki bentuk yang teratur dan sederhana. Menurut (Setyani, 2013), pada saat menggambar, daun di letakkan di atas kertas milimeter dengan mengikuti pola daun, sehingga lebar daun diperkirakan sesuai jumlah kotak yang ada pada pola daun. Dan untuk biomassa tanaman baik berat basah maupun berat kering ditimbang setelah tinggi, jumlah daun, dan lebar daun telah dihitung. Adapun teknik analisis data yang digunakan dalam mengolah data dari hasil penelitian pertumbuhan cabai merah keriting (Capsicum annumm L.), dianalisis menggunakan uji ANOVA yang digunakan dalam penelitian eksperimen yaitu Analisis of Variansi (ANOVA) One Way menggunakan aplikasi SPSS versi 26.

Adapun Kriteria uji ANOVA, jika diketahui $F_{\text {tabel }}<F_{\text {hitung, maka tidak ada }}$ pengaruh dan sebaliknya, jika $F_{\text {hitung }}>$ $F_{\text {tabel }}$ maka terdapat pengaruh. Apabila hasil uji ANOVA didapatkan terdapat pengaruh, maka selanjutnya akan di uji menggunakan uji Least Significant Difference (LSD), Jika didapatkan nilai sig $<0.05$, maka memiliki perbedaan rata-rata yang sangat nyata, dan sebaliknya jika didapatkan nilai sig > 0.05, maka memiliki perbedaan nilai rata-rata yang tidak nyata.

\section{HASIL DAN PEMBAHASAN}

Berikut data hasil rata-rata pertumbuhan tinggi tanaman, jumlah daun, lebar daun, berat basah dan berat kering yakni tanaman tanpa perlakuan (P0) dan tanaman yang diberi suara musik (P1) pada tabel 1 dibawah ini: 
Tabel 1. Rata-rata ulangan tinggi tanaman

\begin{tabular}{cccccccccccc}
\hline Tinggi & \multicolumn{10}{c}{ Ulangan Tinggi Tanaman $(\mathbf{c m})$} \\
\cline { 2 - 14 } Tanaman & Awal & I & II & III & IV & V & VI & VII & VIII & XI & X \\
\hline P0 & 2,5 & 4,13 & 5,14 & 4,38 & 3,5 & 4,98 & 4,43 & 4,63 & 5,02 & 4,5 & 3,96 \\
\hline P1 & 2,5 & 7,85 & 6,79 & 7,61 & 9,17 & 6,55 & 6,2 & 8,09 & 9,98 & 7,25 & 7,48 \\
\hline
\end{tabular}

Dari tabel di atas, dapat dilihat bahwa hasil dari rata-rata ulangan tinggi cabai merah keriting, dengan jumlah ulangan sebanyak 10 kali percobaan, didapatkan bahwa tanaman yang telah diberi suara musik (P1), memiliki rata-rata tinggi tanaman lebih besar dibandingkan tanaman cabai merah keriting yang tanpa perlakuan (P0). Adapun gambar histogram dari rata-rata ulangan tinggi tanaman dapat dilihat pada gambar 1 dibawah ini:

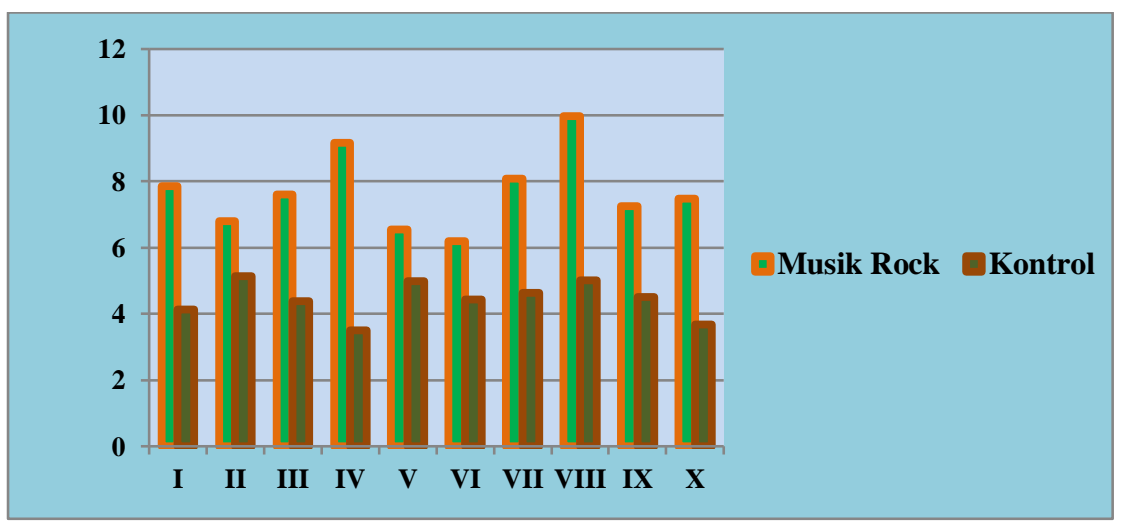

Gambar 1. Histogram rata-rata ulangan tinggi tanaman

Berdasarkan gambar histogram di atas, diketahui bahwa rata-rata ulangan untuk tinggi cabai merah keriting yang di beri perlakuan, memiliki rata-rata yang lebih tinggi dibandingkan pada tanaman yang tanpa perlakuan.

Tabel 2. Hasil Rata-Rata Kumulatif Tinggi Tanaman

\begin{tabular}{cc}
\hline Tinggi Tanaman & Jumlah Rata-Rata (cm) \\
\hline $\mathrm{P} 0$ & 4,5 \\
\hline $\mathrm{P} 1$ & 7,7 \\
\hline
\end{tabular}

Rata-rata kumulatif pertumbuhan tinggi cabai merah keriting, yang diperoleh bahwa tinggi tanaman P1 lebih tinggi dengan jumlah rata-rata $7,7 \mathrm{~cm}$, dibandingkan dengan tanaman P0 dengan jumlah rata-rata $4,5 \mathrm{~cm}$. 
Tabel 3. Rata-Rata Ulangan Jumlah Daun Tanaman

\begin{tabular}{cccccccccccc}
\hline \multirow{2}{*}{$\begin{array}{c}\text { Jumlah } \\
\text { Daun }\end{array}$} & \multicolumn{10}{c}{ Ulangan Jumlah Daun (helai) } \\
\cline { 2 - 12 } & Awal & I & II & III & IV & V & VI & VII & VIII & XI & X \\
\hline P0 & 4 & 4,1 & 5,4 & 5,1 & 4,5 & 5,2 & 5,3 & 5,1 & 5,4 & 5,1 & 4,6 \\
\hline P1 & 4 & 8,2 & 6,6 & 7,2 & 6,2 & 5,9 & 7,5 & 7,7 & 6,2 & 7,2 & 7,3 \\
\hline
\end{tabular}

Dari tabel di atas, dapat dilihat yang telah diberi suara musik bahwa hasil dari rata-rata ulangan memiliki rata-rata jumlah daun tanaman jumlah daun cabai merah keriting, lebih besar dibandingkan tanaman cabai dengan jumlah ulangan sebanyak $10 \mathrm{kali}$ merah keriting yang tanpa perlakuan percobaan, didapatkan bahwa tanaman $\quad$ (P0).

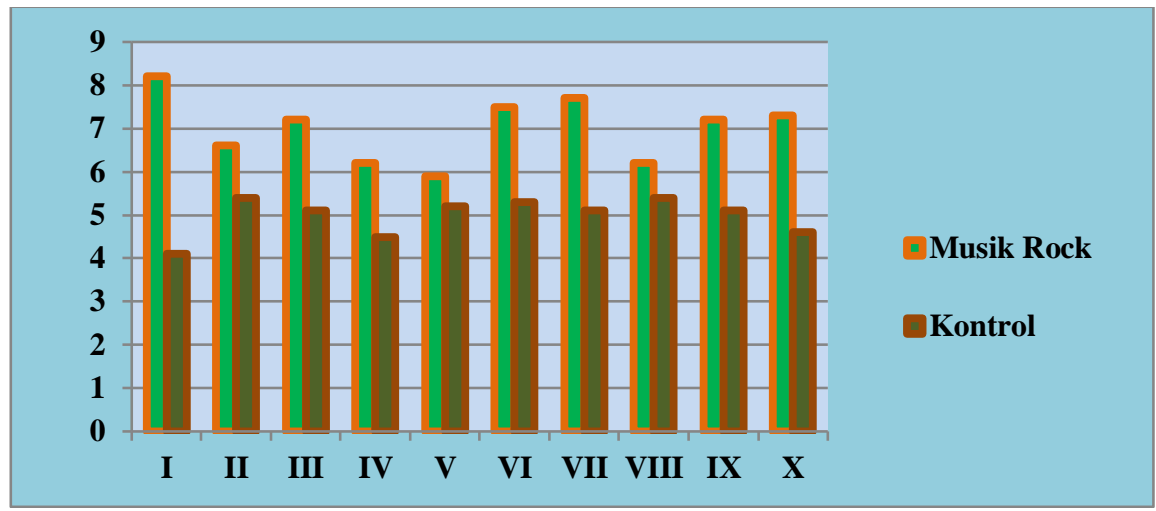

Gambar 2. Histogram rata-rata ulangan jumlah daun tanaman

Berdasarkan gambar histogram di atas, diketahui bahwa rata-rata ulangan untuk jumlah daun tanaman yang diberi perlakuan memiliki rata-rata yang lebih tinggi dibandingkan pada tanaman tanpa perlakuan.

Tabel 4. Hasil rata-rata kumulatif jumlah daun tanaman

\begin{tabular}{cc}
\hline Jumlah Daun & Jumlah Rata-Rata (helai) \\
\hline P0 & 4,4 \\
\hline P1 & 7 \\
\hline
\end{tabular}

Rata-rata kumulatif pertumbuhan jumlah daun cabai merah keriting, yang diperoleh bahwa jumlah daun tanaman
P1 lebih tinggi dengan jumlah rata-rata 7 helai, dibandingkan dengan tanaman P0 dengan jumlah rata-rata 4,4 helai. 
Tabel 5. Rata-Rata Ulangan Lebar Daun Tanaman

\begin{tabular}{cccccccccccc}
\hline \multirow{2}{*}{$\begin{array}{c}\text { Lebar } \\
\text { Daun }\end{array}$} & \multicolumn{10}{c}{ Ulangan Lebar Daun Tanaman (cm) } \\
\cline { 2 - 24 } & Awal & I & II & III & IV & V & VI & VII & VIII & XI & X \\
\hline P0 & 4 & 11 & 17 & 13,7 & 8,5 & 16,3 & 13 & 8,7 & 21,5 & 13,7 & 9,5 \\
\hline P1 & 4 & 28,7 & 17,9 & 22,5 & 23,3 & 19 & 18 & 23,7 & 31 & 23,9 & 25,1 \\
\hline
\end{tabular}

Dari tabel di atas, dapat dilihat bahwa hasil dari rata-rata ulangan lebar daun cabai merah keriting, dengan jumlah ulangan sebanyak 10 kali percobaan, didapatkan bahwa tanaman yang telah diberi suara musik $(\mathrm{P} 1)$ memiliki rata-rata lebar daun lebih besar dibandingkan tanaman cabai merah keriting yang tanpa perlakuan (P0). Adapun gambar histogram dari rata-rata ulangan lebar daun tanaman:

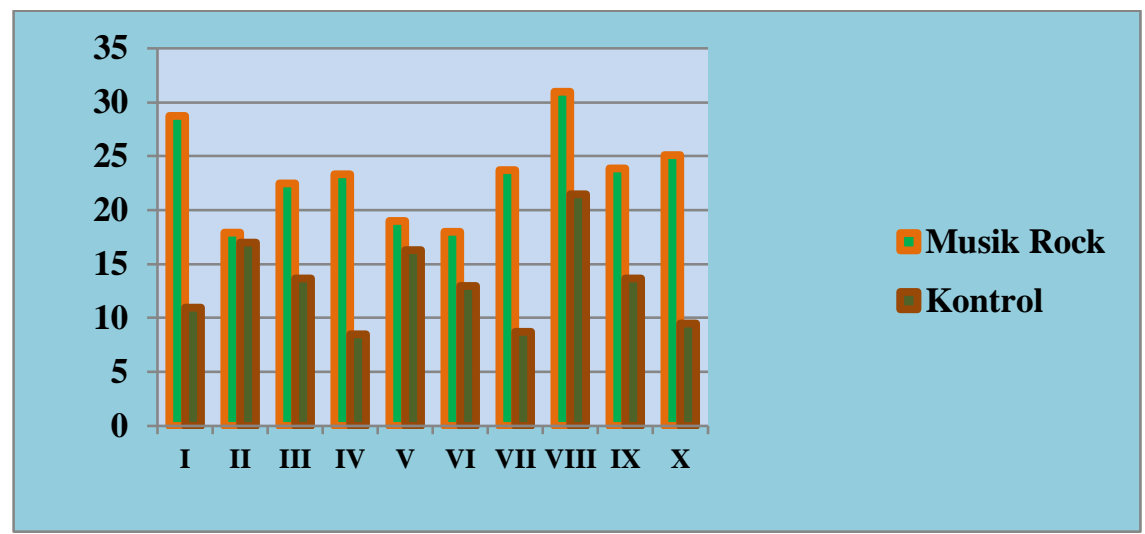

Gambar 3. Histogram rata-rata ulangan lebar daun tanaman

Berdasarkan gambar histogram di memiliki rata-rata yang lebih tinggi atas, diketahui bahwa rata-rata ulangan dibandingkan pada tanaman yang tanpa untuk lebar daun yang diberi perlakuan perlakuan.

Tabel 6. Hasil Rata-Rata Kumulatif Lebar Daun Tanaman

Lebar Daun

\begin{tabular}{ll}
\hline P0 & 13,29 \\
\hline P1 & 23,31 \\
\hline
\end{tabular}

Rata-rata kumulatif pertumbuhan lebar daun cabai merah keriting, yang diperoleh bahwa jumlah daun tanaman
P1 lebih tinggi dengan jumlah rata-rata 23,31 $\mathrm{cm}$ dibandingkan dengan tanaman $\mathrm{P} 0$ dengan jumlah rata-rata $13,29 \mathrm{~cm}$. 
Tabel 7. Rata-Rata Biomassa Tanaman

\begin{tabular}{|c|c|c|c|c|c|c|c|c|c|c|c|}
\hline \multirow{2}{*}{$\begin{array}{l}\text { Biomassa } \\
\text { Tanaman }\end{array}$} & \multicolumn{11}{|c|}{ Ulangan Biomassa Tanaman (gram) } \\
\hline & I & II & III & IV & $\mathrm{V}$ & VI & VII & VIII & $\mathrm{XI}$ & & \\
\hline \multirow{2}{*}{ P0 } & BB0 & 1,5 & 1,5 & 1,5 & 1,5 & 1,5 & 1,5 & 1,5 & 1,5 & 1,5 & 1,5 \\
\hline & BK0 & 0,3 & 0,3 & 0,3 & 0,3 & 0,3 & 0,3 & 0,3 & 0,3 & 0,3 & 0,3 \\
\hline \multirow{2}{*}{ P1 } & BB1 & 3 & 3 & 4 & 4 & 3 & 3 & 4 & 7 & 4 & 3 \\
\hline & BK1 & 0.9 & 0.9 & 0.9 & 0.9 & 0.9 & 0.9 & 0.9 & 3 & 0.9 & 0.9 \\
\hline
\end{tabular}

Dari tabel di atas, dapat dilihat bahwa hasil dari rata-rata ulangan biomassa cabai merah keriting, dengan jumlah ulangan sebanyak 10 kali percobaan, didapatkan bahwa tanaman yang telah diberi suara musik (P1), memiliki rata-rata biomassa lebih besar dibandingkan cabai merah keriting yang tanpa perlakuan (P0).

Tabel 8. Hasil rata-rata kumulatif biomassa tanaman

\begin{tabular}{cccc}
\hline \multicolumn{2}{c}{ Biomassa Tanaman } & & Jumlah Rata-Rata (gram) \\
\cline { 2 - 4 } \multirow{2}{*}{ P0 } & BB0 & 1,5 \\
\cline { 2 - 3 } & \multirow{2}{*}{ P1 } & BK0 & 0,3 \\
\cline { 2 - 3 } & BB1 & 3,8 \\
\hline
\end{tabular}

Rata-rata kumulatif pertumbuhan biomassa cabai merah keriting, yang diperoleh bahwa biomassa tanaman P1 lebih tinggi, dengan berat basah rata-rata 3,8 gram sedangkan berat kering 1,1 gram dibandingkan dengan tanaman $\mathrm{P} 0$ dengan berat basah rata-rata 1,5 gram sedangkan berat kering 0,3 gram.

Data parameter pertumbuhan tanaman cabai merah keriting (Capsicum annum L.), yaitu tinggi batang, jumlah daun, lebar daun dan biomassa tanaman baik tanaman yang diberi suara musik (P1) maupun tanaman yang tanpa perlakuan (P0), selanjunya akan dianalisis menggunakan uji ANOVA yaitu Analisis of Variansi (ANOVA) One Way. Uji ANOVA dilakukan untuk mengetahui bagaimanakah pengaruh penggunaan music terhadap pertumbuhan cabai merah keriting (Capsicum annum L.).

Data hasil pertumbuhan tanaman sebelum melakukan uji One Way Anova, terlebih dahulu melakukan uji Normalitas Shapiro Wilk, dan uji Homogenitas. Adapun hasil data uji Normalitas Shapiro Wilk dan uji Homogenitas dapat dilihat di lampiran. 
Pada data hasil uji ANOVA, $>F_{\text {tabel }}$ maka terdapat pengaruh. Data

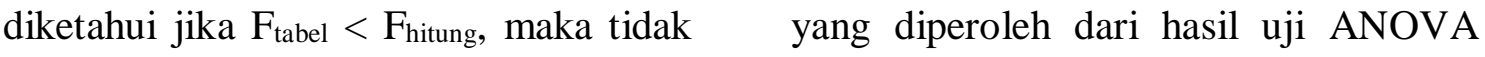
ada pengaruh dan sebaliknya, jika $F_{\text {hitung }}$ yakni,

Tabel 9. Hasil Uji ANOVA Tinggi Batang

\begin{tabular}{lccccc}
\hline \multicolumn{7}{c}{ ANOVA } \\
\hline Hasil & Sum of Squares & Df & $\begin{array}{c}\text { Mean } \\
\text { Square }\end{array}$ & F & Sig. \\
\hline Between Groups & 52.165 & 1 & 52.165 & 64.500 & .000 \\
\hline Within Groups & 14.558 & 18 & .809 & & \\
\hline Total & 66.722 & 19 & & & \\
\hline
\end{tabular}

Tabel 10. Hasil Uji ANOVA Jumlah Daun

\begin{tabular}{lccccc}
\hline \multicolumn{7}{c}{ ANOVA } \\
\hline Hasil & Sum of Squares & Df & $\begin{array}{c}\text { Mean } \\
\text { Square }\end{array}$ & F & Sig. \\
\hline Between Groups & 20.402 & 1 & 20.402 & 54.844 & .000 \\
\hline Within Groups & 6.696 & 18 & .372 & & \\
\hline Total & 27.098 & 19 & & \\
\hline
\end{tabular}

Tabel 11. Hasil Uji ANOVA Lebar Daun

\begin{tabular}{lccccc}
\hline \multicolumn{7}{c}{ ANOVA } \\
\hline Hasil & Sum of Squares & Df & $\begin{array}{c}\text { Mean } \\
\text { Square }\end{array}$ & F & Sig. \\
\hline Between Groups & 502.002 & 1 & 502.002 & 27.988 & .000 \\
\hline Within Groups & 322.858 & 18 & 17.937 & & \\
\hline Total & 824.860 & 19 & & & \\
\hline
\end{tabular}

Tabel 12. Hasil Uji ANOVA Berat Basah

\begin{tabular}{lccccc}
\hline \multicolumn{7}{c}{ ANOVA } \\
\hline Hasil & Sum of Squares & Df & Mean Square & F & Sig. \\
\hline & 26.450 & 1 & 26.450 & 35.007 & .000 \\
\hline Between Groups & 13.600 & 18 & .756 & & \\
\hline Within Groups & 40.050 & 19 & & & \\
\hline Total & & &
\end{tabular}

Tabel 13. Hasil Uji ANOVA Berat Kering

\begin{tabular}{cccccc}
\hline \multicolumn{7}{c}{ ANOVA } \\
\hline & Hasil & & \\
\hline & Sum of Squares & Df & $\begin{array}{c}\text { Mean } \\
\text { Square }\end{array}$ & F & Sig. \\
\hline Between Groups & 3.281 & 1 & 3.281 & 14.878 & .001 \\
\hline Within Groups & 3.969 & 18 & .220 & & \\
\hline Total & 7.250 & 19 & & & \\
\hline
\end{tabular}




\section{Berat kering didapatkan}

bahwa $F_{\text {hitung }}=14.878$, sedangkan $F_{\text {tabel }}=$ 4.41, maka $F_{\text {hitung }}>F_{\text {tabel. }}$. Hal tersebut menunjukkan bahwa, nilai di setiap parameter pertumbuhan pada tanaman cabai merah keriting diperoleh $\mathrm{F}_{\text {hitung }}>$

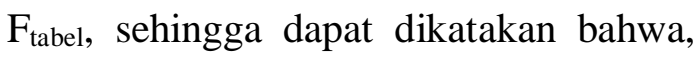
penggunaan music berpengaruh secara nyata terhadap pertumbuhan cabai merah kering (Capsicum annum L.).

Setelah uji ANOVA telah dilakukan, selanjutnya akan diuji lebih lanjut menggunakan uji Least Significant Difference (LSD). Uji LSD/Uji BNt (Beda Nyata Terkecil), digunakan untuk mengetahui lebih lanjut rata-rata parameter pertumbuhan tanaman yang berpengaruh secara signifikan. Jika didapatkan nilai sig $<0.05$, maka memiliki perbedaan rata-rata yang sangat nyata, dan sebaliknya jika didapatkan nilai sig $>0.05$, maka memiliki perbedaan nilai rata-rata yang tidak nyata. Adapun hasil uji LSD/BNt sebagai berikut:

Tabel 14. Hasil Uji LSD Tinggi Tanaman

\begin{tabular}{|c|c|c|c|c|c|c|}
\hline \multicolumn{7}{|c|}{$\begin{array}{lc}\text { Multiple Comparisons } \\
\end{array}$} \\
\hline \multicolumn{7}{|c|}{ Dependent Variable: HASIL } \\
\hline \multicolumn{7}{|l|}{ LSD } \\
\hline \multirow{2}{*}{$\begin{array}{c}\text { (I) } \\
\text { penelitian }\end{array}$} & \multirow{2}{*}{$\begin{array}{c}(\mathbf{j}) \\
\text { penelitian }\end{array}$} & \multirow{2}{*}{$\begin{array}{c}\text { Mean } \\
\text { Differen } \\
\text { ce }(\mathbf{I}-J)\end{array}$} & \multirow{2}{*}{$\begin{array}{l}\text { Std. } \\
\text { Error }\end{array}$} & \multirow[b]{2}{*}{ Sig. } & \multicolumn{2}{|c|}{ 95\% Confidence Interval } \\
\hline & & & & & Lower Bound & $\begin{array}{l}\text { Upper } \\
\text { Bound }\end{array}$ \\
\hline Tinggi p0 & Tinggi $\mathrm{p} 1$ & $\begin{array}{c}- \\
3.23000^{*}\end{array}$ & .89651 & $\begin{array}{c}.00 \\
1\end{array}$ & -5.0111 & -1.4489 \\
\hline \multicolumn{4}{|c|}{$\begin{array}{l}\text { Tinggi Batang, hasil uji LSD/BNt, } \\
\text { menunjukkan bahwa nilai signifikan } \\
\text { antara tinggi batang P1-P0 adalah sig } \\
0.001<0.05 \text {, yang menunjukkan bahwa }\end{array}$} & \multicolumn{3}{|c|}{$\begin{array}{l}\text { rata-rata tinggi batang memiliki } \\
\text { perbedaan yang sangat signifikan } \\
\text { diantara tinggi batang tersebut. }\end{array}$} \\
\hline \multicolumn{7}{|c|}{ Tabel 15. Hasil Uji LSD } \\
\hline \multicolumn{7}{|c|}{ Multiple Comparisons } \\
\hline \multicolumn{7}{|c|}{ Dependent Variable: HASIL } \\
\hline \multicolumn{7}{|c|}{ LSD } \\
\hline \multirow{2}{*}{$\begin{array}{c}\text { (I) } \\
\text { penelitia } \\
n\end{array}$} & \multirow{2}{*}{$\begin{array}{c}\mathbf{j}) \\
\text { penelitia } \\
\mathbf{n}\end{array}$} & \multirow{2}{*}{$\begin{array}{c}\text { Mean } \\
\text { Differen } \\
\text { ce }(\mathbf{I}-\mathbf{J})\end{array}$} & \multirow[b]{2}{*}{$\begin{array}{l}\text { Std. } \\
\text { Error }\end{array}$} & \multicolumn{3}{|c|}{ 95\% Confidence Interval } \\
\hline & & & & Sig. & $\begin{array}{l}\text { Lower } \\
\text { Bound }\end{array}$ & $\begin{array}{l}\text { Upper } \\
\text { Bound }\end{array}$ \\
\hline $\begin{array}{c}\text { Jumlah } \\
\text { Daun p0 }\end{array}$ & $\begin{array}{c}\text { Jumlah } \\
\text { Daun p1 }\end{array}$ & $-2.02000^{*}$ & .89651 & .027 & -3.8011 & -.2389 \\
\hline
\end{tabular}


Tabel 16. Hasil Uji LSD Lebar Daun

Multiple Comparisons

\begin{tabular}{|c|c|c|c|c|c|c|}
\hline \multicolumn{7}{|c|}{ Dependent Variable: HASIL } \\
\hline \multicolumn{7}{|l|}{ LSD } \\
\hline \multirow{2}{*}{$\begin{array}{c}\text { (I) } \\
\text { penelitian }\end{array}$} & \multirow{2}{*}{$\begin{array}{c}(\mathbf{j}) \\
\text { penelitian }\end{array}$} & \multirow{2}{*}{$\begin{array}{c}\text { Mean } \\
\text { Differenc } \\
\text { e (I-J) }\end{array}$} & \multirow{2}{*}{$\begin{array}{l}\text { Std. } \\
\text { Error }\end{array}$} & \multirow{2}{*}{ Sig. } & \multicolumn{2}{|c|}{$\begin{array}{c}\text { 95\% Confidence } \\
\text { Interval }\end{array}$} \\
\hline & & & & & $\begin{array}{l}\text { Lower } \\
\text { Bound }\end{array}$ & $\begin{array}{l}\text { Upper } \\
\text { Bound }\end{array}$ \\
\hline $\begin{array}{c}\text { Lebar } \\
\text { Daun p0 }\end{array}$ & $\begin{array}{c}\text { Lebar } \\
\text { Daun p1 }\end{array}$ & $\begin{array}{c}- \\
10.02000^{*}\end{array}$ & .89651 & .000 & -11.8011 & -8.2389 \\
\hline
\end{tabular}

Tabel 17. Hasil Uji LSD Berat Basah

\begin{tabular}{|c|c|c|c|c|c|c|}
\hline \multicolumn{7}{|c|}{ Multiple Comparisons } \\
\hline \multicolumn{7}{|c|}{ Dependent Variable: HASIL } \\
\hline \multicolumn{7}{|l|}{ LSD } \\
\hline \multirow{2}{*}{$\begin{array}{c}\text { (I) } \\
\text { penelitia } \\
\mathbf{n}\end{array}$} & \multirow{2}{*}{$\begin{array}{c}(\mathbf{j}) \\
\text { penelitia } \\
\mathbf{n}\end{array}$} & \multirow{2}{*}{$\begin{array}{c}\text { Mean } \\
\text { Differen } \\
\text { ce (I-J) }\end{array}$} & \multirow{2}{*}{$\begin{array}{l}\text { Std. } \\
\text { Error }\end{array}$} & \multirow{2}{*}{ Sig. } & \multicolumn{2}{|c|}{$\begin{array}{c}\text { 95\% Confidence } \\
\text { Interval }\end{array}$} \\
\hline & & & & & $\begin{array}{l}\text { Lower } \\
\text { Bound }\end{array}$ & $\begin{array}{l}\text { Upper } \\
\text { Bound }\end{array}$ \\
\hline $\begin{array}{c}\text { Berat } \\
\text { Basah } \\
\text { p0 }\end{array}$ & $\begin{array}{c}\text { Berat } \\
\text { Basah p1 }\end{array}$ & $-2.30000^{*}$ & .89651 & .012 & -4.0811 & -.5189 \\
\hline
\end{tabular}

Tabel 18. Hasil Uji LSD Berat Kering

\begin{tabular}{|c|c|c|c|c|c|c|}
\hline \multicolumn{7}{|c|}{ Multiple Comparisons } \\
\hline \multicolumn{7}{|c|}{ Dependent Variable: HASIL } \\
\hline \multicolumn{7}{|l|}{ LSD } \\
\hline \multirow{2}{*}{$\begin{array}{c}\text { (I) } \\
\text { peneliti } \\
\text { an }\end{array}$} & \multirow{2}{*}{$\begin{array}{c}\text { (j) } \\
\text { peneliti } \\
\text { an }\end{array}$} & \multirow{2}{*}{$\begin{array}{c}\text { Mean } \\
\text { Differen } \\
\text { ce }(\mathbf{I}-\mathbf{J})\end{array}$} & \multirow[b]{2}{*}{$\begin{array}{c}\text { Std. } \\
\text { Error }\end{array}$} & \multirow[b]{2}{*}{ Sig. } & \multicolumn{2}{|c|}{ 95\% Confidence Interva } \\
\hline & & & & & $\begin{array}{l}\text { Lower } \\
\text { Bound }\end{array}$ & $\begin{array}{l}\text { Upper } \\
\text { Bound }\end{array}$ \\
\hline Berat & Berat & & & & & \\
\hline $\begin{array}{l}\text { Kering } \\
\text { p0 }\end{array}$ & $\begin{array}{c}\text { Keringp } \\
1\end{array}$ & $-.81000^{*}$ & .89651 & .369 & -2.5911 & .9711 \\
\hline
\end{tabular}

Berat Kering, hasil uji LSD/BNt, rock yang memiliki tingkat kebisingan menunjukkan bahwa nilai signifikan dan frekuensi yang tinggi, dapat antara berat kering P1-P0 adalah sig $0,369>0,05$, yang menunjukkan bahwa rata-rata berat kering memiliki perbedaan yang tidak signifikan diantara berat kering tersebut. Dalam penelitian ini ditemukan bahwa penggunaan musik

mempengaruhi parameter pertumbuhan tanaman cabai merah keriting (Capsicum annum L.), yang sesuai dengan pendapat (Yulianto, 2008: 149), frekuensi 3.500$5.000 \mathrm{~Hz}$ dapat merangsang pembukaan stomata, dan menurut pendapat Carlson 
D, dalam Nadliroh et al (2015: 187), frekuensi 3,5-5 $\mathrm{KHz}$ dapat merangsang pembukaan stomata/mulut daun dan meningkatkan laju fotosintesis dari tinggi tanaman. Selama penelitian, musik rock dimainkan setiap hari, dan hasilnya menunjukkan bahwa itu dapat mempengaruhi tinggi tanaman secara signifikan, tinggi tanaman yang awalnya $2.5 \mathrm{~cm}$, dan setelah pengukuran mencapai $13.8 \mathrm{~cm}$, dengan penambahan tinggi tanaman mengalami peningkatan di setiap pengukuran dibandingkan dengan tanaman cabai merah keriting yang tanpa perlakuan. Hal ini didukung dengan adanya uji LSD/BNt, dan hasilnya berbeda secara nyata. Pemutaran musik rock tidak hanya mempengaruhi tinggi tanaman, tetapi juga mempengaruhi parameter jumlah daun, di mana rata-rata jumlah daun yang awalnya 4,2 helai, setelah pengukuran mencapai 9,7 helai, dan ratarata lebar daun yang awalnya $8,2 \mathrm{~cm}$ setelah akhir pengukuran mencapai 40,3 $\mathrm{cm}$, dan biomassa tanaman diperoleh berat rata-rata $\mathrm{BB}$ 3,8 gram dan berat rata-rata $\mathrm{BK}$ 1,11 gram. Hasil penelitian ini ditemukan bahwa musik rock dapat mempengaruhi parameter pertumbuhan tanaman cabai merah keriting (Capsicum annum L.), tidak hanya mempengaruhi tinggi tanaman, jumlah daun, dan biomassa tanaman. Parameter lebar daun tanaman pun berpengaruh nyata terhadap penggunaan musik rock dibandingkan tanaman yang tanpa perlakuan.

Penggunaan teknologi gelombang suara tersebut, dapat mendorong pertumbuhan tanaman, dengan menggunakan frekuensi suara yang dapat berpengaruh positif terhadap pertumbuhan cabai merah keriting (Capsicum annum L.). Menurut pendapat (Damayanti, 2016: 46), saat fotosintesis terjadi, gelombang suara yang dihasilkan dapat meningkatkan penyerapan karbon dioksida. Adanya getaran suara dapat merangsang mulut daun (stomata), tetap membuka dan melebar, sehingga memenuhi kebutuhan nutrisi, hal ini sejalan dengan pendapat (Kadarisman et al., 2011: 464). Pembukaan stomata, dapat menyerap nutrisi lebih efektif, meningkatkan kecepatan fotosintesis. Pemenuhan nutrisi yang baik tersebut, secara langsung dapat mempengaruhi pesatnya pertumbuhan aktivitas vegetatif tanaman, seperti pemanjangan dan peningkatan sel pada tanaman itu sendiri, sesuai dengan Chivukula \& Shivaraman, dalam Rusmiyanto \& Wulandari Rousdy (2018: 12), musik yang dipaparkan dapat berpengaruh dalam metabolisme tanaman dan mengaktifkan enzim. 


\section{KESIMPULAN}

Berdasarkan hasil penelitian tersebut, dapat disimpulkan bahwa: pemutaran musik rock dengan tingkat kebisingan dan frekuensi tinggi, dapat berpengaruh secara nyata terhadap parameter pertumbuhan cabai merah keriting (Capsicum annum L), antara lain: tinggi tanaman, jumlah daun tanaman, lebar daun tanaman, dan biomassa tanaman. Penelitian ini menunjukkan bahwa, nilai di setiap parameter pertumbuhan cabai merah keriting diperoleh $F_{\text {hitung }}>F_{\text {tabel}}$, sehingga dapat dikatakan bahwa, ada pengaruh penggunaan musik rock terhadap pertumbuhan cabai merah keriting (Capsicum annum L.).

\section{UCAPAN TERIMA KASIH}

Terima kasih saya ucapkan kepada semua pihak yang telah berpartisipasi pada penelitian saya, terutama kepada dosen pembimbing yang telah membantu saya dalam menyelesaikan tugas akhir ini. Terima kasih pula kepada segenap unsur pimpinan FKIP UMMA yang telah memberikan saya tempat untuk menimbah ilmu dan memberikan ruang untuk dapat melakukan penelitian.

\section{DAFTAR PUSTAKA}

Damayanti, R. A. (2016). Pengaruh pemberian suara garengpung (Dundubia manifera) dengan intensitas waktu tertentu terhadap pertumbuhan tanaman jahe merah (Zingiber officinale). Skripsi. Tidak diterbitkan. Yogyakarta: Fakultas Keguruan dan Ilmu Pendidikan Universitas Sanata Dharma. https://repository.usd.ac.id/6579/

Dwicaksono, M. R. B., Suharto, B., \& Susanawati, L. D. (2013). Pengaruh Penambahan Effective Microorganisms pada Limbah Cair Industri Perikanan Terhadap Kualitas Pupuk Cair Organik. Jurnal Sumberdaya Alam Dan Lingkungan, 1, (1): 7-11.

https://jsal.ub.ac.id/index.php/js al/article/view/99

Kadarisman, N., Purwanto, A., \& Rosana, D. (2011). Rancang Bangun Audio Organic Growth System ( Aogs ) Melalui Spesifikasi Spektrum Bunyi Binatang Alamiah Sebagai Local Genius Untuk Peningkatan Kualitas Dan Produktivitas Tanaman Holtikultura. Prosiding Seminar Nasional Penelitian, Pendidikan Dan Penerapan MIPA. Universitas Negeri Yogyakarta, 14 Mei 2011. http://staffnew.uny.ac.id/upload/132 135229/penelitian/Rancang+Bangu n+Audio+Organic+Growth+System + (Nur+Kadarisman, + Agus + Purwan to,+Dadan+Rosana).pdf.pdf

Made, S. (2015). Bahan Ajar Perancangan Percobaan. Denpasar: Universitas Udayana. 
Nadliroh, K., S. Widodo, C., \& R. Santoso, D. (2015). Analisis Pengaruh Frekuensi Bunyi Terhadap System Buka Tutup Stomata Tanaman Padi Varietas Logawa. Natural-B, 3, (2): 187192. https://naturalb.ub.ac.id/index.php/naturalb/article/download/296/252

Rosalina. (2014). Pengaruh Penggunaan Musik Rock Terhadap Perumbuhan Cabai Rawit ( Capsicum annuum) dan Cabai Keriting (Capsicum frutescens). Skripsi. Tidak diterbitkan. Yogyakarta: Fakultas Keguruan Ilmu Pendidikan Universitas Sanata Dharma. https://repository.usd.ac.id/22303/

Rusmiyanto, E. P., \& Wulandari Rousdy, D. (2018). Efek Paparan Musik Klasik, Hard Rock dan Murottal Terhadap Pertumbuhan Vegetatif Tanaman Bayam Merah (Alternanthera amoena Voss). Jurnal Protobiont, 7, (3): 9-14. https://jurnal.untan.ac.id/index.php/ jprb/article/download/29063/75676 $\underline{578779}$

Setyani, Y.H., Anwar, S., \& Slamet, W. (2013). Karakteristik Fotosintetik Dan Serapan Fosfor Hijauan Alfalfa (Medicago sativa) Pada Tinggi Pemotong Dan Pemupukan Nitrogen Yang Berbea Animal. Agricultural Journal, 2 (1): 86-96. https://www.neliti.com/id/publicati ons/186602/karakteristik-

fotosintetik-dan-serapan-fosforhijauan-alfalfa-medicago-sativa-pa

Soekamto, M. H., \& Fahrizal, A. (2019). Upaya Peningkatan Kesuburan Tanah Pada Lahan Kering Di Kelurahan Aimas Distrik Aimas Kabupaten Sorong. Abdimas:
Papua Journal of Community Service, $1 \quad$ (2): 14. https://doi.org/10.33506/pjcs.v1i2.6 $\underline{70}$

Suparman, A. (2006). Bercocok Tanam Cabai. Jakarta: Azka Press.

Sugiono, (2010). Metode Penelitian Kuantitatif Kualitatif dan $R \& D$, Penerbit Alfabet.

Suyanti. (2020). Membuat 6 Olahan Cabai. Jakarta: Penebar Swadaya.

Utami. (2012). Aplikasi musik klasik, pop dan hard rock terhadap pertumbuhan vegetatif tanaman cabai merah keriting (Capsicum annuum var. longum (DC.) Sendtn). https://repository.unri.ac.id/bitstrea $\mathrm{m} /$ handle/123456789/3456/Karya\% 20Ilmiah\%20Silvia\%20Utami.pdf?s equence $=1 \&$ is Allowed $=y$

Vebriansyah, R. (2020) Tingkatkan Produktivitas Cabai. Jakarta: Penebar Swadaya.

Yulianto. (2008). Penerapan Teknologi Sonic Bloom dan Pupuk Organik untuk Peningkatan Produksi Bawang Merah (Studi Kasus Bawang Merah di Brebes, Jawah Tengah). J. Argoland, 15 (3):. 148155.

http://jurnal.untad.ac.id/jurnal/index .php/AGROLAND/article/downloa d/183/151 